\title{
Projeto Lótus: Um relato da transformação de máquinas caça-níqueis em computadores de apoio ao ensino fundamental
}

\author{
Fabrício Bortoluzzi ${ }^{1}$, Hendrig Wernner ${ }^{1}$, Ana Carolina R. Carneiro ${ }^{3}$, \\ Renate Raabe ${ }^{1}$, André Raabe ${ }^{1,2,3}$ \\ ${ }^{1}$ Bacharelado em Ciência da Computação \\ ${ }^{2}$ Mestrado em Computação Aplicada \\ ${ }^{3}$ Programa de Pós-Graduação em Educação \\ Universidade do Vale do Itajaí - Univali
}

$\{f b$, hendrig, anacaroolinarc, renateraabe, raabe $\} @$ univali.br

\begin{abstract}
This paper describes the working model adopted by the Lotus Project for the transformation of slot machines on computers with the Linux operating system and the educational suite GCompris as an effort to improve digital inclusion in the municipal schools of fundamental education in Balneario Camboriu, SC. The results obtained between 2009 and 2012 were the installation of 12 laboratories in the schools of early childhood education, 122 computers and a total of 2,433 students favored.

Resumo. Este artigo descreve o modelo de trabalho adotado pelo Projeto Lótus para a transformação de máquinas caça-níqueis em computadores com o sistema operacional Linux e a suíte educacional GCompris como um esforço para melhorar a inclusão digital nas escolas municipais do ensino fundamental em Balneário Camboriú, SC. Os resultados obtidos entre 2009 e 2012 foram a instalação de 12 laboratórios nos núcleos de educação infantil, 122 computadores e um total de 2.433 estudantes favorecidos.
\end{abstract}

\section{Introdução}

Hoje, dentre diversos fatores, os esforços educacionais se concentram na inclusão da escola no mundo tecnológico da informação e comunicação, visto o processo de globalização vigente. Pensar em infraestrutura educacional requer adaptar os espaços escolares de maneira a atender a demanda das inovações e promover a inclusão digital.

O projeto Lótus, descrito neste artigo, busca contribuir para inclusão digital alinhado com o que propõe o Projeto de Lei do Plano Nacional de Educação para o decênio 2011-2020, o qual estabelece diretrizes para a promoção humanística, científica e tecnológica do país estabelecendo metas relacionadas a universalização do acesso à rede mundial de computadores, o aumento da relação computadores/estudantes nas escolas públicas e de educação básica e outros. O objetivo maior é promover a utilização pedagógica das tecnologias da informação e de comunicação (Brasil 2010). 
Peculiar nesta iniciativa é o fato da origem dos equipamentos ser proveniente de ações de contravenção, especificamente a captura de caça-níqueis, um jogo de azar ${ }^{1}$, que de acordo com BRASIL (1946), são proibidos no país desde 1946.

Recentemente tornou-se comum a presença de máquinas de jogos de azar, ou caça-níqueis, em locais como bares e mesmo a formação de casas de jogos clandestinas. Isto se deve a diversos fatores, entre eles a realidade social e econômica, a dificuldade das polícias em fiscalizar os ambientes de jogos itinerantes - criados em casas residenciais alugadas por curtos períodos de tempo - e pela facilidade com que o maquinário pode ser obtido.

A Universidade do Vale do Itajaí atendeu ao pedido do Ministério Público de Santa Catarina, de analisar a viabilidade e propor uma solução para o reaproveitamento das centenas de máquinas caça-níqueis apreendidas, sob posse das polícias civil e militar, no município de Balneário Camboriú, SC. Desde então, o Laboratório de Redes de Computadores, vinculado aos cursos de Ciência da Computação e Sistemas para a Internet, vem entregando kits de hardware, software e cursos de capacitação para as escolas municipais desta cidade.

Este artigo busca relatar este trabalho com dois enfoques: (i) relatar a experiência enfatizando os desafios e escolhas de ordem tecnológica envolvidas, servindo como referencia para projetos similares; (ii) e avaliar a viabilidade e condições para continuidade da iniciativa enquanto política pública para inclusão digital.

$\mathrm{O}$ artigo está organizado como segue: a seção 2 descreve o modelo de transformação adotada enfatizando os papeis das entidades envolvidas; a seção 3 discute aspectos ligados a busca de viabilidade financeira do projeto; a seção 4 relata as transformações realizadas de ordem física, hardware e software para montagem dos kits educacionais; a seção 5 apresenta os resultados em termos de escolas atendidas; a seção 6 apresenta discussões.

\section{Modelo de trabalho}

O Projeto Lótus é uma realização resultante de ações diretas e específicas da Polícia Militar do Estado de Santa Catarina, do Ministério Público de Santa Catarina, da Prefeitura Municipal de Balneário Camboriú e da Universidade do Vale do Itajaí. A Figura 1 ilustra o processo de trabalho desenvolvido.

\footnotetext{
${ }^{1}$ Os Jogos de azar são aqueles em que a possibilidade de ganhar ou perder não dependem das habilidades do jogador, mas sim exclusivamente de seu azar.
} 


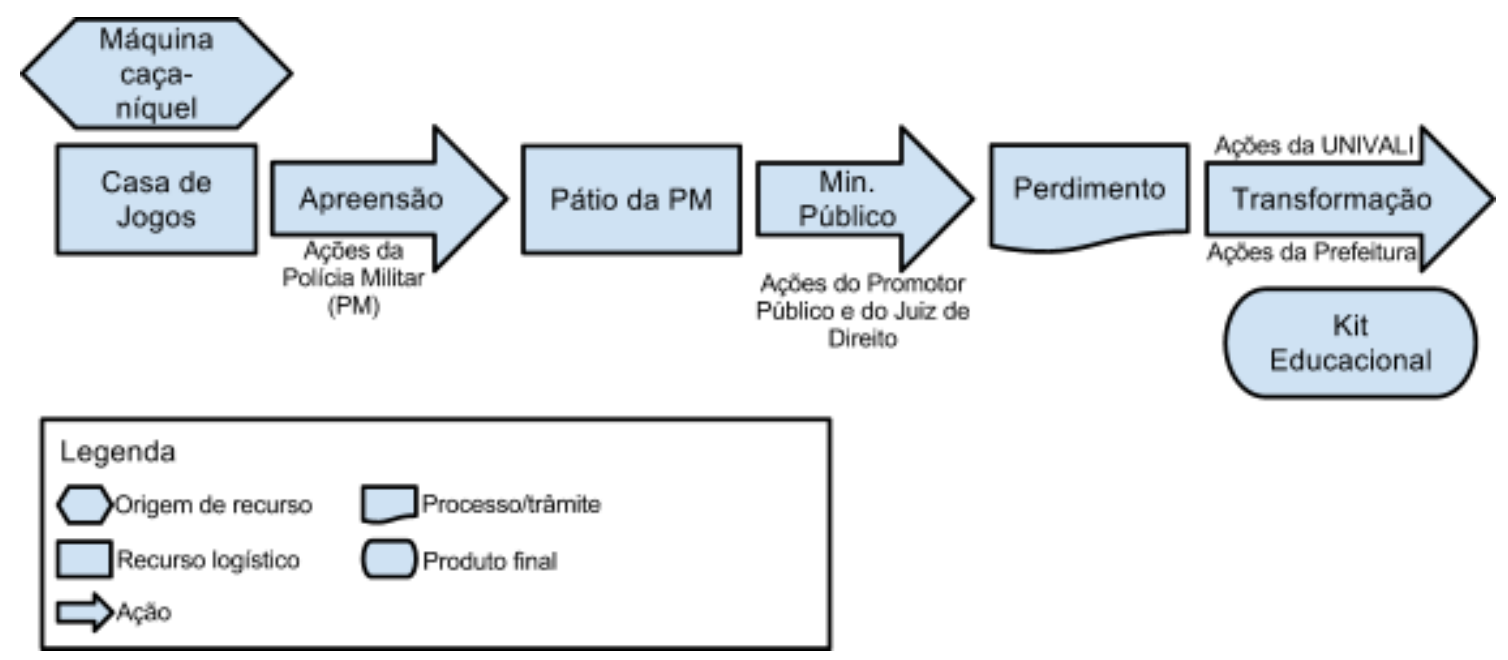

Figura 1. Processo de trabalho do Projeto Lótus

A Polícia Militar realiza apreensões de máquinas caça-níqueis em casas de jogos clandestinas, bares, casas temporárias alugadas e similares. Normalmente, o material apreendido é transportado pelos próprios oficiais e destinado ao pátio de apreensões. As peças de informática são colocadas em caixas de armazenamento, as partes de madeira MDF grandes são separadas para reaproveitamento. As peças não reaproveitáveis, como leitores de cédulas e botões de apostas são inutilizadas através de quebra com martelo e destinadas para descarte adequado.

É necessário que este material permaneça sob posse da Polícia Militar até que o Ministério Público, através de seu Promotor Público, realize os procedimentos para a pena de perdimento, onde o contraventor abre mão de reivindicar suas posses aprendidas como parte da pena, complementada normalmente por multa em dinheiro. Assim, o material aproveitável pode ser encaminhado sob denominação de doação, evitando, por exemplo, estabelecimento de vínculo de fiel depositário.

Um funcionário da Secretaria Municipal de Educação e um Bolsista do Projeto trabalham simultaneamente no galpão realizando as atividades necessárias para transformar a máquina caça-níqueis em computador. Lá elas também recebem o pendrive, que substitui o disco rígido, contendo os softwares de operação e a suíte educacional. Uma pessoa responsável pela coordenação dos laboratórios de informática decide quais unidades de ensino devem receber estes kits e aciona os pedidos de instalação elétrica e demais adequações físicas.

Caso os professores necessitem, é agendada uma tarde de treinamento para os mesmos. Em geral, não leva mais do que 4 horas para que um professor ambiente-se por completo com as atividades e consiga preparar sessões de uso das ferramentas. Neste ponto finaliza o processo de trabalho, complementado apenas pelas etapas de manutenção e feedback descritos adiante.

\section{Perseguindo a Viabilidade}

As adaptações de transformação devem ser viáveis. Existem dois riscos principais levantados na época de idealização do projeto. O primeiro é de conformidade financeira e o segundo, de conformidade ambiental. 


\subsection{Viabilidade financeira}

Uma máquina caça-níquel contém muitos componentes de um computador tradicional, entretanto, não todos. Em geral, as peças físicas que faltam para que ela se torne um computador são: teclado, mouse, gabinete e disco rígido. A aquisição destes itens é inevitável, exceto pelo disco rígido. O Projeto Lótus fez escolhas no sentido de minimizar os gastos com estas aquisições para preservar o máximo de viabilidade financeira e maximizar a quantidade de unidades produzidas.

Ao invés da aquisição de discos rígidos com valores a partir de $R \$ 150,00$, emprega-se pendrives para a mesma finalidade, com custo de apenas $R \$ 18,00$. Naturalmente, ao invés de se ter dezenas ou centenas de gigabytes para armazenamento, o sistema operacional e aplicações são acomodadas em unidades de apenas 2 gigabytes e, na prática, ocupam menos da metade deste espaço, graças ao uso de técnicas de compressão e sistemas completos, porém leves.

O restante dos materiais que tornam possível a transformação. A Tabela 1 detalha os custos da última aquisição de cada material, no primeiro semestre de 2012.

Tabela 1.Custo das principais adquiridas pelo Projeto.

\begin{tabular}{|c|c|}
\hline Peça & Custo da última aquisição em 50 unidades \\
\hline Gabinete de computador padrão Mini-ATX & $\mathrm{R} \$ 45,00$ \\
\hline Pendrive com 2 gigabytes de armazenamento & $\mathrm{R} \$ 16,00$ \\
\hline Teclado padrão ABNT-2 & $\mathrm{R} \$ 18,00$ \\
\hline Mouse óptico & $\mathrm{R} \$ 15,00$ \\
\hline
\end{tabular}

A aquisição de gabinetes com ou sem fonte de alimentação varia conforme o estoque de fontes em bom estado obtidas durante as separações de material. Os demais itens são sempre necessários.

De um modo geral, considera-se o Projeto como financeiramente viável porque o custo de uma transformação é muito inferior ao custo que seria necessário para a aquisição de computadores novos. Salienta-se também que o montante destinado para a aquisição destes materiais origina-se das multas que os próprios infratores pagam para livrarem-se do processo judicial.

\subsection{Viabilidade ambiental}

Apenas uma fração das máquinas apreendidas permanece em um estado aproveitável. Algumas vezes é necessário que as peças passem por perícia técnica antes do perdimento. Este procedimento requer o desencaixe do processador, memórias e dispositivos de entrada e saída. Outras vezes não é possível garantir proteção total às intempéries durante a fase de armazenamento ou do transporte pós-apreensão. Isto não é um problema comprometedor, pois a quantidade de unidades apreendidas é alta quando comparada as unidades transformadas, mas gera lixo que não pode ser descartado por meios comuns. 
Para tratar desta conformidade, uma etapa foi adicionada de tal forma que uma empresa especializada em descartes de componentes eletrônicos se compromete a coletar periodicamente o material inútil ao projeto e encaminhar para reciclagem. Como garantia do cumprimento destes mecanismos, a empresa precisa ser capaz de emitir um certificado de conformidade ambiental, atividade esta regulamentada pelo Instituto Brasileiro do Meio Ambiente e dos Recursos Naturais Renováveis (IBAMA).

As regras estabelecidas em comum acordo entre as partes envolvidas é a coleta mensal ou de acordo com a demanda, sem custo ou lucro aos participantes, exceto à empresa certificada para os descartes.

\section{Transformações realizadas: de caça níqueis a kits educacionais}

As peças de informática são transportadas em veículos da Secretaria Municipal de Educação ou da Prefeitura Municipal para um galpão de trabalho, com espaço, bancadas, alimentação elétrica e aparatos tradicionais que permitam testes $\mathrm{e}$ manipulação de placas-mãe, memórias, processadores, adaptadores de vídeo e rede e demais componentes de hardware. Já as peças de marcenaria: chapas de MDF, dobradiças, parafusos e finalizações metálicas, são levadas para um ambiente de marcenaria da própria prefeitura, para receber modificações conforme as condições de cada laboratório que recebe os computadores. Existem três formatos possíveis para a entrega, ilustrados na Figura 2.

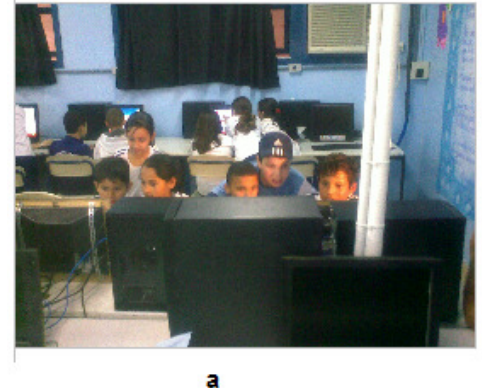

$\mathbf{a}$

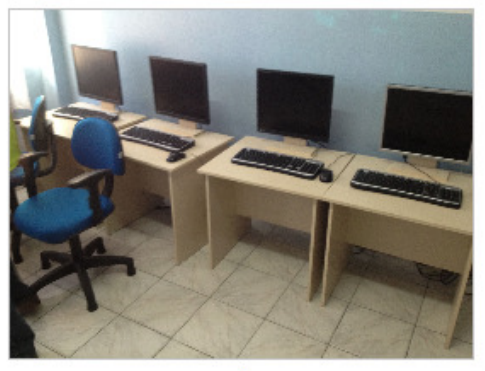

b

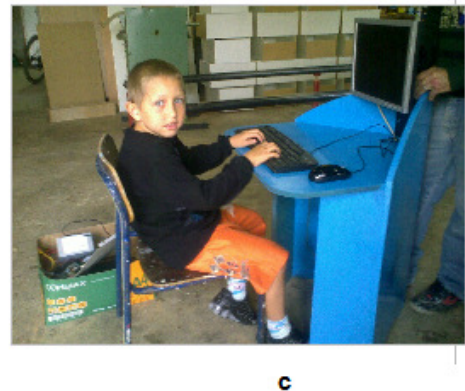

Figura 2. Formato tradicional (a), formato modular (b) e formato adaptado (c).

Nos casos em que o laboratório de informática contemplado já possui uma bancada apropriada para computadores, o Projeto Lótus entrega os kits de computador em formato tradicional (Figura 2a), isto é, gabinetes comuns com monitores em pedestais, teclado e mouse. Quando o laboratório requer idealização a partir de uma sala de aula comum, então entregam-se bancadas criadas de forma modular, com proteção para que o gabinete da máquina não entre em contato com o utilizador do equipamento (Figura 2b). Desde o início das montagens, ensaia-se também um formato adaptado (figura 2c), criado com as chapas de MDF apreendidas e o computador já embutido dentro delas.

\subsection{Sistema operacional e suíte educacional}

Para ser funcional, o computador oferecido pelo Projeto Lótus deve ser interessante do ponto de vista pedagógico. Isto exige a escolha de softwares capazes de funcionarem em diferentes perfis de hardware apreendido, do mais antigo ao mais novo, com diferentes fabricantes de componentes e, de preferência, ocultando detalhes para evitar retrabalhos. Os produtos escolhidos para comporem a porção de software das máquinas 
transformadas tiveram seu potencial pedagógico e viabilidade técnica, testados e aprovados em pesquisa anterior (RAABE et. al. 2008) e consistem de um sistema operacional e uma suíte educacional.

O sistema operacional adotado é o Ubuntu, um sistema operacional completo para computadores. Ele utiliza o núcleo do Linux e pode receber um conjunto de 25 mil programas para as mais diversas finalidades, entre elas, a educacional. Tanto o Debian quanto os programas são distribuídos em um modelo de software livre que isenta o integrador de qualquer tipo de pagamento por licenças. (Ubuntu, 2012).

A suíte educacional adotada é a GCompris. GCompris é um conjunto de 122 atividades voltadas para crianças de 2 a 10 anos de idade. Oferece desafios de coordenação motora, como os de manipulação do mouse e do teclado, atividades que imitam jogos de tabuleiro, como o xadrez e damas e também recursos auxiliares como o aprendizado das horas, de desenho, quebra-cabeças com pinturas famosas e diagramas montáveis. (GCOMPRIS, 2010).

A Figura 3 exibe três atividades. Em (a) está o Jogo de Memória. Nele deve-se encontrar os pares que relacionam uma coleção de desenhos em uma carta (no exemplo, seis estrelas), com a carta contendo o número correspondente (no exemplo, o número 2, que é uma associação incorreta).

Entretanto, o que mais chama a atenção destes pesquisadores no GCompris são as atividades complementares à sala de aula: em (b) está a atividade de Associação. Nela deve-se escolher uma entre diversas palavras que representa corretamente a imagem exibida. No exemplo, há três opções: banana, livro e casa para a imagem de uma banana. Em (c), outra aplicação do ensino de português: deve-se escolher uma entre diversas letras para formar corretamente a palavra correspondente à imagem exibida. As vogais "e", "a" e "o" aparecem como opção para formar "carro".
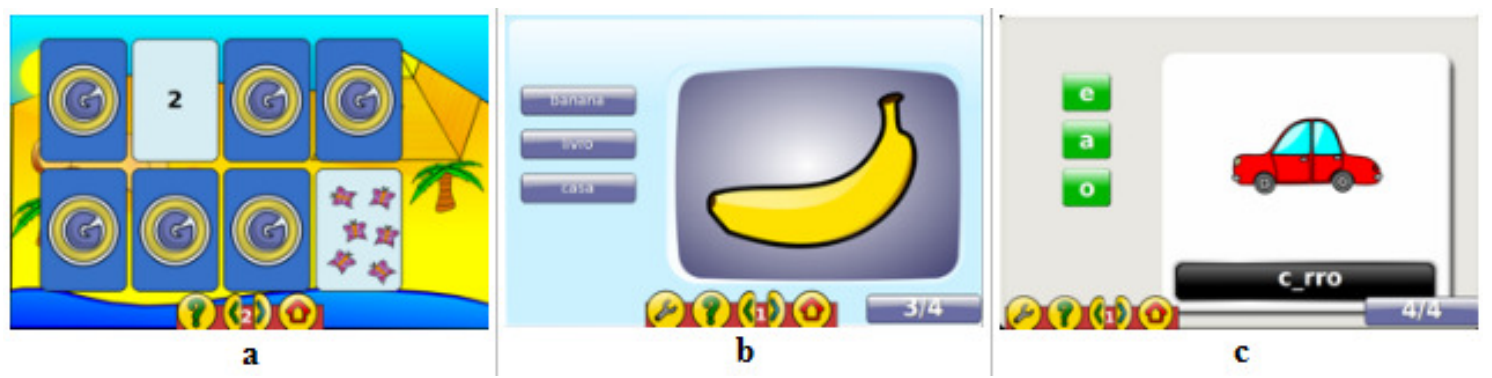

Figura 3. Diversas telas da Suíte Educacional GCompris.

É na aplicação desta suite que reside o diferencial do Projeto Lótus. Foi deixada de lado a prática comum de simplesmente tratar a transformação do caça-níquel como um quiosque de uso geral para em seu lugar oferecer uma plataforma de apoio sistemático e efetivo de educação e inclusão digital.

Entende-se que muito mais ainda pode ser feito em relação as escolhas de software educacionais para comporem a suíte, porém o projeto tinha necessidade de rapidamente atender ao chamado feito pelo Ministério Público, neste sentido a adoção de mais pacotes de softwares educativos bem como a avaliação de outros sistemas operacionais de cunho educacional foi delegada para pesquisas futuras. 


\section{Resultados obtidos}

O Projeto Lótus é um trabalho em andamento. A etapa de produção dos kits iniciou-se em agosto de 2009 e os indicadores físicos são descritos na Tabela 2.

Tabela 2. Indicadores físicos de resultado.

\begin{tabular}{|l|c|c|}
\hline \multicolumn{1}{|c|}{ Escola (Núcleo de Educação Infantil - NEI) } & Computadores & Alunos \\
\hline Anjo da Guarda & 8 & 100 \\
\hline Carrossel & 10 & 210 \\
\hline Cristo Luz & 11 & 136 \\
\hline Novo Tempo & 15 & 259 \\
\hline Odácia Tereza Damazio & 10 & 280 \\
\hline Pão e Mel & 8 & 280 \\
\hline Pequeno Mundo & 10 & 69 \\
\hline Pioneiros & 10 & 136 \\
\hline Rio das Ostras & 10 & 121 \\
\hline São Judas Tadeu & 9 & 390 \\
\hline Sementes do Amanhã & 12 & 288 \\
\hline Vovô Alécio & $\mathbf{1 2 2}$ & $\mathbf{2 4 3 3}$ \\
\hline Total & & \\
\hline
\end{tabular}

As 122 unidades transformadas foram distribuídas para formar 12 diferentes laboratórios nos Núcleos de Educação Infantil. Ficou estabelecido que cada escola pode receber até 20 computadores, variando conforme o espaço físico e a quantidade de alunos matriculados.

$\mathrm{Na}$ medida em que novas remessas de apreensões tornam-se disponíveis, a Secretaria Municipal de Educação, em sua assessoria de informática, define quais devem ser as próximas escolas beneficiadas.

Cursos de capacitação são disponibilizados sob demanda com os idealizadores do projeto e os professores das escolas. Tais treinamentos são realizados, frequentemente, logo após a instalação das máquinas no núcleo.

\section{Discussões}

O Projeto Lótus já colhe os frutos de seu propósito. Hoje, aulas são realizadas regularmente nos laboratórios de informática atendendo a diversas turmas nas escolas atendidas. Neste sentido, entende-se que o projeto auxilia na promoção da inclusão digital, uma vez que em seu sentido mais comum, esta pode ser vista como um meio de democratizar o acesso às tecnologias da informação. Parte-se do princípio em que ela só ocorre quanto há a efetiva estrutura, técnica e o domínio dela, para a real 
democratização. O projeto serve de subsídio e ponto de partida para o aprimoramento deste meio visto à realidade em questão. Segundo Rondelli (apud NEVES e GOMES, 2008) quatro passos são necessários para a inclusão digital: a oferta de computadores conectados em rede; a criação de oportunidades para que os aprendizados feitos a partir dos suportes técnicos digitais possam ser empregados no cotidiano da vida e do trabalho; a necessidade de políticas públicas e pesquisas que subsidiem as estratégias de inclusão digital; e a exploração do potencial interativo da mídia digital.

Assim como qualquer artefato tecnológico, os kits podem sofrer danos por desgaste, falhas ou mau uso. Os relatos deste tipo de ocorrência são sanados através da troca de peças in loco. Já o feedback sobre a qualidade dos softwares e os ajustes para inserção de novos aplicativos faz um caminho mais lento, uma vez que existe a necessidade de discussão do teor pedagógico e a regravação dos softwares armazenados no pendrive.

O retorno medido por avaliação informal junto aos professores de laboratório após os cursos de capacitação indica uma percepção positiva com relação à missão do Projeto Lótus. No entanto, salienta-se que este é dos principais aspectos a serem aprimorados no projeto, uma vez que entende-se que a criação de possibilidades educacionais mediadas por tecnologia deve ser um processo realizado em parceria como os professores nas escolas. Uma sistemática que retroalimente o processo e possibilite continua avaliação e aprimoramentos dos recursos de hardware e software envolvidos deve ser incluída no projeto.

O Projeto Lótus é decorrência de uma política pública em sua definição mais comum: aquela caracterizada como iniciativa para solução das dificuldades encontradas na sociedade (SOUZA, 2006). Neste sentido, vislumbra-se a possibilidade de manutenção desta política desde que três condições permaneçam satisfatórias: (i) a insistência dos infratores em montar novos espaços com novas máquinas caça-níqueis, (ii) a subsequente apreensão destas pela Polícia; e (iii) a necessidade de computadores para as escolas.

Com relação ao primeiro fator, é possível afirmar que a natureza turística da cidade combinada com a fração de seus visitantes habituados ao jogo, mesmo que ilegal, acaba por colaborar com a existência desta prática em números muito superiores a outras cidades de diferente perfil. A Polícia Militar de Balneário Camboriú relata apreensões em bases mensais, onde obtém, geralmente, 20 ou mais máquinas em cada apreensão que realiza. É a partir destes indicadores que se pode estabelecer as futuras atividades do Projeto.

Até o momento, apenas 12 das 40 escolas de Balneário Camboriú foram contempladas. Considerando a possibilidade de que todas as unidades possuem espaço e receptividade para acomodar ao menos um laboratório que acomode entre 8 e 12 computadores, ainda é possível. Além disso as máquinas apresentam alto índice de problemas de hardware o que gera uma necessidade de troca frequente dos equipamentos.

Outra possibilidade que, por consenso entre as partes, foge do escopo atual dos trabalhos, é contemplar centros de aprendizado diferenciados, como as APAEs (Associação dos Pais e Amigos dos Excepcionais), APAVIs (Associação dos Portadores de Artrite e Artrose do Vale do Itajaí), creches e outras entidades públicas de missão 
educacional. Eventualmente estes locais receberão kits do Projeto, exigindo, para tal, um reestudo da suite educacional com enfoque em adequação ao público alvo.

Concluindo, acredita-se que ao colaborar para disponibilização de kits educacionais nas escolas, o projeto tende a impulsionar um conjunto de mudanças subsequentes para apoio a formação de indivíduos mais preparados para o futuro, estando alinhado com o pensamento de (Morais e Almeida, 2011) que menciona que no caso específico do uso de TIC em escolas, seja para processos de ensino e aprendizagem ou para inclusão social e digital, desencadeiam maior participação de todos os setores socio-estatais, via comunidades escolares na formulação e gestão do planejamento em uma área fundamental para a formação da pessoa contemporânea.

\section{Referências}

BRASIL. Decreto-Lei no 9215, de 30 de abril de 1946. Proíbe os jogos de azar no Brasil. Diário Oficial [da República Federativa do Brasil], Brasília.

BRASIL. Projeto de Lei que aprova o Plano Nacional de Educação para o decênio 2011-2020. Ministério da Educação, Brasília: 2010.. Disponível em: <http://portal.mec.gov.br>. Acesso em: 20 de março de 2012.

DEBIAN. Website oficial do debian. Disponível em [http://www.debian.org]. Acesso em 23 de março de 2010.

GCOMPRIS. Website oficial do gcompris. Disponível em [http://www.gcompris.net]. Acesso em 24 de março de 2010.

NERI, Marcelo. Mapa da Inclusão Digital. Rio de Janeiro, Fundação Getúlio Vargas, 2012.

NEVES, Barbara Coelho; GOMES, Henriette Ferreira A inclusão digital e o contexto brasileiro: uma experiência nos domínios de uma universidade. Universidade de Barcelona, 2008. Disponível em: [http://goo.gl/15Czn]. Acesso em: 01 de agosto de 2012.

MORAIS, Andrei S.; ALMEIDA, Doriedson A. Políticas Públicas para a Informática na Educação: reflexões sobre desafios contemporâneos. Simpósio Brasileiro de Informática na Educação SBIE 2011, Anais..., Aracaju, 2011.

RAABE, Renate O. ; BORTOLUZZI, F. ; SILVA JR., F. ; OLIVEIRA, A. . Uma experiência do uso do Software Livre GCOMPRIS na aprendizagem de crianças do Ensino Fundamental. In: XXVIII Congresso da Sociedade Brasileira de Computação, 2008, Belém do Pará. Anais do Workshop sobre Informática na Escola, 2008. p. 332341.

SOUZA, Celina. Políticas públicas: numa revisão da literatura. Sociologias, Porto Alegre, ano 8, n 16, jul/dez 2006, p. 20-45 